\title{
Estimation of sex using discriminant function analysis of percutaneous finger lengths in Nepalese adults
}

\author{
Walung ED', Maharjan RM', Shrestha R'
}

'Eugen Dolma Walung, 'Mani Raj Maharjan, 'Rijen Shrestha, Lecturers; Department of Forensic Medicine, Maharajgunj Medical Campus, Institute of Medicine, Kathmandu, Nepal.

\begin{abstract}
Background: Disasters are a common occurrence in Nepal. This necessitates the development of baseline forensic anthropological data specific to the Nepalese population. Recent advances in the field of forensic medicine and sciences have somewhat reduced the relevance of forensic anthropology in the western developed world. The financial burden of these newer techniques, however, puts emphasis back on methodological examination of remains to establish identity. Objectives: To establish the sex of the individual from the percutaneous length of the fingers.

Methodology: One hundred and twenty medical students (58 males and 62 females) were randomly selected and their finger lengths measured. These measurements were analyzed to establish discriminant functions to estimate sex.

Results: The equation derived was $Y=(1.822 \times$ Left index finger length $)+(1.141 \times$ Left little finger length $)-19.211$. Group centroids were calculated to be -0.933 for females and 0.998 for males. The sensitivity was found to be $76.9 \%$ and a specificity of $78.2 \%$. Overall, the function correctly classified $77.5 \%$ of the original cases.

Conclusion: Based on these findings, finger length is as reliable in estimation of sex of an individual as other longs bones and can be an ideal tool for examination, especially in remains where the skull and pelvis are absent or missing.
\end{abstract}

Key words: Discriminant function; Forensic anthropology; Forensic medicine.

DOI: https://doi.org/10.3126/jkmc.v8i2.28167

\section{INTRODUCTION}

$\mathrm{E}$ xamination of human remains in routine forensic cases rarely requires the establishment of identity using scientific standards. In most cases, the family members can recognize the deceased based on various physical characteristics as well as personal belongings. However, it is not uncommon to encounter remains that are beyond recognition, nor is it uncommon to find remains that do not have belongings or documents that could provide a clue as to the identity of the individual. Furthermore, forensic practitioners are expected to examine mutilated remains as well as skeletonized human remains that require extensive examination and investigation for establishment of identity.

Marty Porcher and Autissier found that work accident accounted for an estimated 3300 of 11000 hand injuries

Address for correspondence

Dr. Mani Raj Maharjan

Lecturer, Department of Forensic Medicine

Maharajgunj Medical Campus, Institute of Medicine

Maharajgunj, Kathmandu, Nepal

E-mail: dr.manimaharjan@iom.edu.np in 1980. In addition, injuries to the hand accounted for one-third of all chronic injuries, and $20 \%$ of permanent disabilities ${ }^{1}$. The use of severing fingers as a means of torture as well as punishment is widely exposed in all cultural setting through cinema. It is also common for limbs, including fingers, to get amputated following violent high velocity impact, for example, following air crashes.

Sex estimation is an extremely important aspect of forensic anthropological investigation. The advances in the last few decades have decreased the need to use anthropological examination for estimation of sex due to the advent of DNA technology and subsequent ability to establish the genetic sex of the individual. However, in low and middle-income countries (LMIC) like Nepal, the financing of DNA tests has proven to be expensive, timeconsuming and requires specialist human resources.

As is the case in all medico-legal investigations, time is of the utmost importance, and therefore, DNA tests, especially for estimation of sex, is not only impractical, 
but also improbable. It is therefore important to develop a reference standard for rapid estimation of sex.

In addition, this reference standard can also be used to estimate the sex of the individual who has left a handprint at the crime scene. Yet again, while DNA would provide a more definite answer, the trace amounts of DNA available would necessitate extremely sensitive test that would invariably require significant financial input as well as require development of highly specialized human resources.

Studies so far conducted have ranged from determination of sex from hand and foot bone length ${ }^{2}$, upper limb measurements ${ }^{3}$, hand dimension ${ }^{4}$, foot index method $^{5}$, index finger length ${ }^{6}$ as well as length ratios of metacarpals and phalanges ${ }^{7}$.

While it may be relatively rare to come across cases in forensic practice, nevertheless, forensic practitioners are thus exposed to a unique dilemma regarding establishing the identity of the same. The sizes, shape, aesthetics as well as other features like coarseness of the palmer skin, hair density and distribution etc. assist in estimating the sex in fresh remains, and these features tend to be less reliable following decomposition. To this end, we look at the possibility of estimating sex, based on finger length measurements.

\section{METHODOLOGY}

The study consisted of 120 (58 males and 62 females) randomly selected medical students, who were posted to Department of Forensic Medicine at the Institute of Medicine, Maharajgung in 2018, aged between 20 to29 years.

\section{Finger length measurements}

Fingers of both hands were measured using standard procedures and landmarks as suggested by Manning et $\mathrm{al}^{8}$ and HV Vallois ${ }^{9}$. All measurements of fingers were taken from the midpoint of the proximal crease at the base of each finger to the tip of respective finger. The finger measurements were taken using standard sliding calipers in centimeters to the nearest millimeter. The measurements were taken by two authors individually, at different times and were blind to the other's findings to avoid bias. The measurements obtained were averaged.

The data was analyzed using Statistical Package for the Social Sciences version 20. The data was analyzed to develop descriptive statistics as well as for discriminant function analysis for estimating sex from finger lengths. Participants with deformities of the fingers, poorly defined proximal flexion crease of fingers, left hand dominance and subjects with history of any injuries to any fingers in the past were excluded from the study.

\section{RESULTS}

The data was collected by two authors, a week apart, with the authors blinded to each other's data. The data collected was tested for inter-observer error using paired sample t-test. The difference in the measurements were found to have no statistical significance $(p<0.01)$.The results are presented in Table 1.

The data was then analyzed for discriminant function analysis, using stepwise method (Criteria for removal $\mathrm{F}<2.71$ ) for estimating sex. The results showed that all the mean value of finger length in males were found to be higher than in females and only left index and left little fingers showed statistically significant $(p<0.001)$ correlation with sex. The Wilk's Lambda for the function was found to be 0.514 , with Eigenvalue of 0.947 and Canonical Correlation of 0.697. The group centroids were calculated to be -0.933 for females and 0.998 for males. The data collected by the two authors was averaged and then descriptive statistics was analyzed as shown in Table 2.

By using discriminant function analysis of left index finger and left little finger, $80.6 \%$ of females, $74.1 \%$ of malesand $77.5 \%$ of original grouped cases were correctly classified. This shows a sensitivity of $76.9 \%$ and a specificity of $78.2 \%$ (Figure 1).

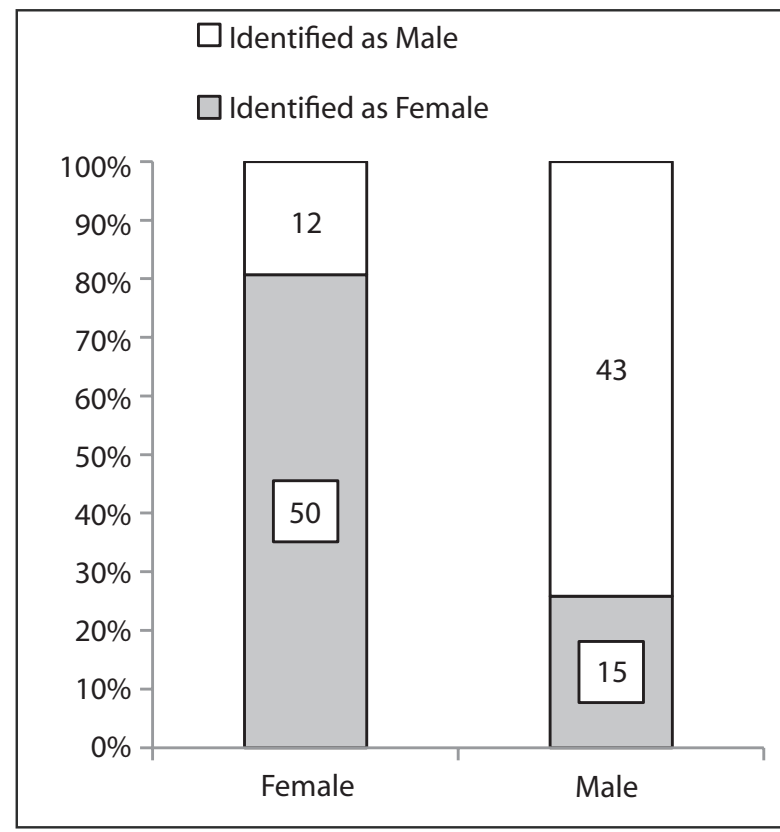

Figure 1: Classification of sex-estimation using derived function 
Table 1: Paired sample t-test showing non-significant inter-observer error in this study group $(\mathbf{n}=120)$

\begin{tabular}{|c|c|c|c|c|c|c|}
\hline \multicolumn{5}{|c|}{ Paired Differences } & \multirow{3}{*}{$\mathbf{T}$} & \multirow{3}{*}{ p-value } \\
\hline & \multirow{2}{*}{ Mean } & \multirow{2}{*}{ Std. Deviation } & \multicolumn{2}{|c|}{$\mathbf{9 5 \%}$ Confidence Interval } & & \\
\hline & & & Lower & Upper & & \\
\hline Right Thumb & -0.0958 & .4267 & -0.1730 & -0.0187 & -2.460 & .015 \\
\hline Right Index & -0.0175 & .4274 & -0.0947 & .0597 & -0.449 & .655 \\
\hline Right Middle & .0617 & .3642 & -0.0042 & .1275 & 1.855 & .066 \\
\hline Right Ring & .0067 & .3705 & -0.0603 & .0736 & .197 & .844 \\
\hline Right Little & .0292 & .4571 & -0.0535 & .1118 & 699 & .486 \\
\hline Left Thumb & -0.0458 & .4008 & -0.1183 & .0266 & -1.253 & .213 \\
\hline Left Index & .0083 & .4070 & -0.0652 & .0819 & .224 & .823 \\
\hline Left Middle & .0533 & .3333 & -0.0069 & .1136 & 1.753 & .082 \\
\hline Left Ring & .0067 & .4409 & -0.0730 & .0864 & .166 & .869 \\
\hline Left Little & .0042 & .5088 & -0.0878 & .0961 & .090 & .929 \\
\hline
\end{tabular}

Table 2: Descriptive statistics of finger measurements in thisstudy group $(n=120)$

\begin{tabular}{lcccc}
\hline & Minimum & Maximum & Mean & Std. Deviation \\
\hline Age & 20.0 & 29.0 & 22.000 & 1.2502 \\
\hline Right Thumb & 4.75 & 7.30 & 6.0396 & .48476 \\
\hline Right Index & 5.65 & 8.00 & 6.9179 & .53800 \\
Right Middle & 5.30 & 9.00 & 7.5325 & .58319 \\
\hline Right Ring & 4.40 & 8.70 & 7.0558 & .58734 \\
\hline Right Little & 4.55 & 7.75 & 5.8388 & .61523 \\
\hline Left Thumb & 4.50 & 7.35 & 5.9663 & .50929 \\
\hline Left Index & 5.20 & 8.00 & 6.8683 & .54833 \\
\hline Left Middle & 5.50 & 8.75 & 7.5425 & .57258 \\
Left Ring & 4.10 & 8.60 & 7.0742 & .61722 \\
\hline Left Little & 4.60 & 7.85 & 5.8721 & .63391 \\
\hline
\end{tabular}

Table 3: Canonical discriminant function coefficients (Un-standardized)

\begin{tabular}{lccc} 
& Function & Wilk's Lambda & p- value \\
Left Index & 1.822 & 0.745 & $<0.001$ \\
Left Little & 1.141 & 0.635 & $<0.001$ \\
(Constant) & -19.211 & & \\
\hline
\end{tabular}

Table 4: Classification results by discriminant function analysis

\begin{tabular}{|c|c|c|c|c|}
\hline \multirow{2}{*}{\multicolumn{2}{|c|}{ Sex }} & \multicolumn{2}{|c|}{ Predicted group membership } & \multirow[b]{2}{*}{ Total } \\
\hline & & Female $\mathbf{n}(\%)$ & Male n (\%) & \\
\hline \multirow{2}{*}{$n=120$} & Female & $50(80.6 \%)$ & $12(19.4 \%)$ & $62(100 \%)$ \\
\hline & Male & $15(25.9 \%)$ & $43(74.1 \%)$ & $58(100 \%)$ \\
\hline
\end{tabular}

\section{DISCUSSION}

Krogman has showed the accuracy of estimation of sex based on different parts of the body. He reported that the availability of the entire skeleton would provide an accuracy of $100 \%$; accuracy would decrease to $98 \%$ with examination of skull and pelvis combined; accuracy would decrease to $95 \%$, following examination of the pelvis alone; further decreasing to $90 \%$ when examining only skull. The accuracy of estimation of sex decreases to $80 \%$, when basing the estimation on long bones ${ }^{10}$. 
Our study showed that the mean value of finger length was found to be greater in male than in female.

The finding of this study also showed an accuracy of $77.5 \%$ in estimating sex from finger length of left index and left little finger by discriminant function analysis. This finding is similar and comparable to the studies conducted by Stojanowski where the use of metacarpal dimension to develop sex estimation found an accuracy ranging between $79 \%$ and $85 \%{ }^{11}$. Similarly another study conducted by Zeljana Basic on mediaeval and modern population of Croatian for estimation of sex from standard skeletal measurement showed statistically significant sexual dimorphism by $74.7 \%^{12}$.

Although long bones are not considered to be the best samples for estimation of sex, in this study finger length showed similar accuracy to other longs bones and was found to be a useful body part to estimate sex when mutilated hands are recovered separately from

\section{REFERENCES}

1. Marty J, Porcher B, Autissier R. Hand injuries and occupational accidents: Statistics and prevention. Annales de chirurgie de la main: organeofficiel des societes de chirurgie de la main. 1983;2(4):368-70. [DOI]

2. Case DT, Ross AH. Sex determination from hand and foot bone lengths. Journal of forensic sciences. 2007 Mar;52(2):264-70. [DOI]

3. Ahmed AA. Estimation of sex from the upper limb measurements of Sudanese adults. Journal of forensic and legal medicine. 2013 Nov;20(8):1041-7. [DOI]

4. Sangeeta D, Kapoor AK. Sex determination from hand dimensions for forensic identification. International Journal of Research in Medical Sciences. 2015 Jun;3(6):1466-72. [DOI]

5. Gupta VP,Shah AH. Sex Determination of Nepalese Medical Students of NAIHS-COM by using Foot Index Method. ACTA scientific medical sciences. 2018 May;2(2). [Full Text]

6. Chauhan A, Tyagi N, Shukla SK. Utilization of Index Finger's Length in StatureEstablishment and Sex Determination of ThePopulation of Rajasthan Region the scene. Furthermore, the authors have tested for inter-observer bias and have shown that when a single protocol is followed, measurements taken by separate individuals have no significant error.

The authors have conducted the study on a relatively small sample size and further testing of the hypothesis on a larger and more geographically varied population would serve to establish a baseline for the entire country.

\section{CONCLUSION}

This study shows that finger length is just as accurate in predicting the sex of an individual as compared to other body parts. The authors propose the following equation to this end:

\section{$Y=1.822 x$ Left Index $+1.141 x$ Left Little -19.211}

The individual is estimated to be a male if $\mathrm{Y}$ is positive and female if $\mathrm{Y}$ is negative.

of India. Journal of forensic science and criminal investigation. 2018 Sept; 10(4).[Full Text]

7. Maryam A, SoheilaG, Ebrahim A, Forouzan F. Sex determination by the length ratio of metacarpals and phalanges: X-ray study on Iranian population. Tehran University Medical Journal. 2018 Nov; 76(8):558-61. [Full Text]

8. Manning JT, Scutt D, Wilson J, Lewis-Jones DI. The ratio of 2 nd to 4 th digit length: a predictor of sperm numbers and concentrations of testosterone, luteinizing hormone and oestrogen. Human Reproduction. 1998 Nov;13(11):3000-4. [DOI]

9. Vallois HV. Anthropometric techniques. CurrAnthropol.1965;6:127-44. [DOI]

10. Iscan MY, Steyn M. The human skeleton in forensic medicine. Charles C Thomas Publisher. 2013;6:22758.

11. Stojanowski CM. Sexing potential of fragmentary and pathological metacarpals. American Journal of Physical Anthropology. 1999 Jun;109(2):245-52. [DOI]

12. Željana B, Ivana K, Ivan J, Deny A,Šimun A. Sex estimation standards for medieval and contemporary Croats. Croat Med J. 2017;58:222-30. [DOI] 